\section{THREE NEW DESIGNS FOR OPERATING SCISSORS}

JACKSON B. TAULBEE, M.D. JOPLIN, MO.

The accompanying illustrations show a set of operating scissors designed by Dr. 'W. H. Taulbee, Maysville, Ky., and myself. The straight ones are combined puncture and dilating scissors. They can be obtained with needle or slightly rounded points. They are of special utility in puncturing, incising and dilating in operations for pelvic abscess and other conditions requiring vaginal incision and drainage. The others are, respectively, sharp-pointed and dull-pointed, right and left, curved dissecting and operating scissors. These are adapted to all work in deep cavities, such as the vagina, bladder, uterus, rectum and throat. The handles of each, being separated by a space when the scissors are closed, do not pinch or catch the folds of loose tissue, mucous membrane or gauze packing, as do those of other scissors; in addition, they may be used to great advantage in deep narrow spaces as retractors

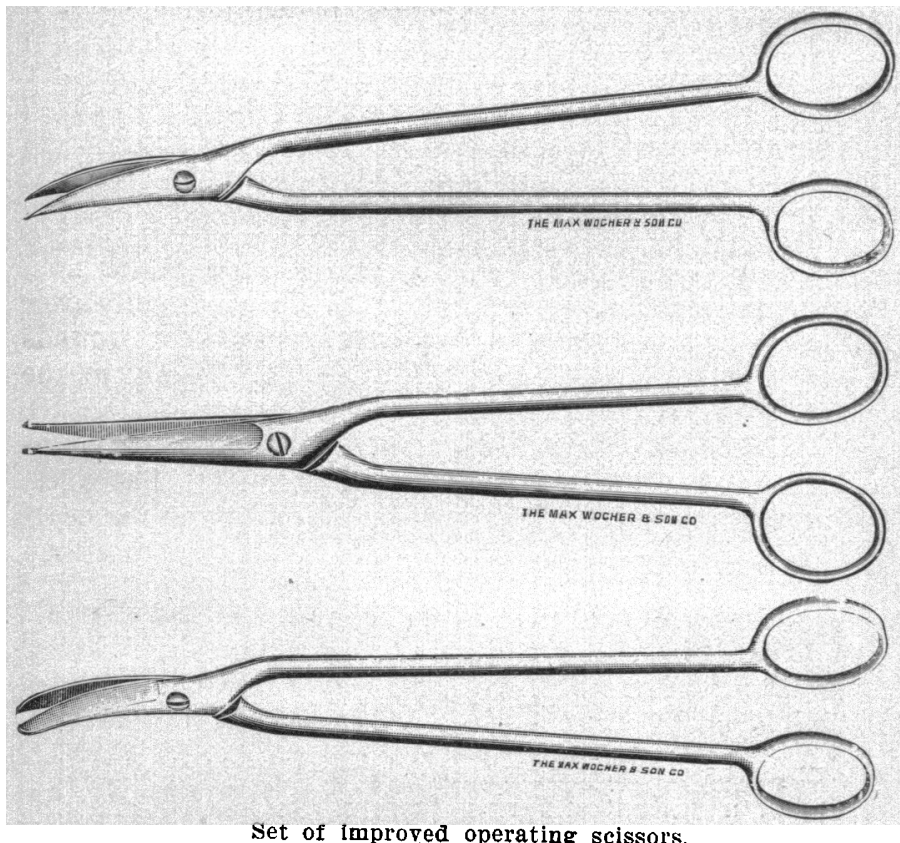

and depressors. The chief advantages common to all three instruments are the spaces between the bars of the handles of each, the length ( $81 / 2$ inches), weight and strength.

311 Wall Street.

\section{BISMUTH POISONING}

TWO CASES, WITH ONE FATALITY, FOLLOWING INJECTION OF BISMUTH-VASELIN PASTE

V. C. DAVID, M.D., AND J. R. KAUFFMAN, M.D.

Members of the House Staff of Cook County Hospital CHICAGO

The injection of bismuth-vaselin paste for the treatment of tuberculous cavities, sinuses and fistulas was introduced by Dr. E. Beck in April, 1908. Its use has been enthusiastically advocated by many and it is now a routine procedure in many of our hospitals. Numerous brilliant results have been reported. The simplicity of the technic, the uncomplicated formula of the mix- ture, and the painlessness of its administration, appeal to all who have charge of these chronic cases.

At the Cook County Hospital bismuth-vaselin paste has been used extensively, not only for tuberculous cavities and sinuses, but for empyemas, fistula in ano, and as bone plugs after mastoid operations, without fear of toxic effect. It is therefore of marked interest to note that in the last four months two cases of bismuth poisoning have occurred following the use of a moderate amount of the paste.

A preliminary report of the cases is made at this time so that it may be more commonly known that toxic effects may result from the use of moderate amounts of bismuth-vaselin paste, and with the hope that conservatism may govern its use until further study establishes more clearly the limit of non-toxic dosage, the manner of its absorption, and the possibility of bismuth idiosyncrasy.

A more detailed report with the laboratory and autopsy findings of the fatal case and the further progress of the convalescent patient will be published later. The analysis of the bismuth used in the paste, and the urinary tests for bismuth, are under the consideration of Dr. Walter S. Haines.

It will be noticed that in both these cases the toxic effects were seemingly produced solely by the bismuth constituent of the subnitrate, no nitrite symptoms (dyspnea, cyanosis, etc.) being observed.

CASE 1.-Patient.-W. E., an American, aged 24, single, bookkeeper, entered Cook County Hospital Aug. 31, 1908, on Dr. Ryerson's service. He gave a history of discharging sinuses about the left hip, which had existed since an injury twenty-one years previously. Examination showed an ankylosed hip with healed and discharging sinuses anteriorly and posteriorly. A clinical diagnosis of tuberculous hip was made.

Bismuth Treatment.-On September 8 three ounces of $331 / 3$ per cent. bismuth-vaselin paste was injected into the sinus on the posterior aspect of the hip. On September 28 a second injection of about six ounces of bismuth paste caused considerable immediate pain to the patient.

Effects of Bismuth:-Pain continued through the night so severe that the patient got scarcely any sleep. On the next day the temperature, which had been normal, rose to $101 \mathrm{~F}$., but returned to 98 in the course of forty-eight hours. The sinus remained open and discharged some pus and small amounts of bismuth paste. Eleven days after the second injection the patient complained, on awakening, of pain in the mouth. From this time on an intense stomatitis rapidly developed. Pain and burning were very severe, and increased so much on attempted mastication and deglutition that the patient took very little of even liquid diet. The gums were swollen and extremely sore. The teeth became loose. A gradually widening, heavy greenish-blue line showed on the gums and on the tip and margins of the tongue. On the left side of the tongue small superficial ulcers appeared, which increased and coalesced until larger than the thumb-nail; the ulcer was covered with a dirty blue-black membrane. The fauces and throat showed the same swollen and pigmented condition. Salivation was constant, intense, and very distressing. Accompanying the stomatitis was some headache and a very marked constipation. The general condition remained fairly good with normal temperature, running to $99 \mathrm{~F}$. only occasionally.

After reaching its height the stomatitis gradually subsided so that at the end of six weeks the ulcerations and salivation had entirely disappeared and the patient was again on regular diet.

The patient complained of continued pain in the hip. An $x$-ray examination showed deposits of bismuth about the joint and a small necrotic focus in the great trochanter, which was removed by operation on December 7. An abscess, which formed in the thigh six days after the operation but which had no demonstrable connection with the operative wound, was 